\title{
Spectroscopic Examination using Density Functional Theory Calculations on 3-chloro-5-methoxyphenol
}

\author{
Palani Murugan, S. Jeyavijayan, M. S. Revathy, K. Gurushankar
}

\begin{abstract}
The complete vibrational assignment of 3-chloro-5-methoxyphenol (CMOP) has been identified by the observed IR and Raman spectral data and vibrational frequencies were calculated by density functional theory method. The ability of the computational method for describing the vibrational modes can be understood by comparing experimental and theoretical spectra. Besides, frontier molecular orbital, Mulliken's charge analyses and molecular electrostatic potential (MEP) surfaces have been computed. The natural bond orbital (NBO) analysis has been studied to analyze the charge delocalization and molecular hyperconjugative interactions.
\end{abstract}

Keywords : DFT calculations, FTIR, FT-Raman, 3-chloro-5-methoxyphenol.

\section{INTRODUCTION}

Phenols derivatives are industrially and biologically important compounds. They are versatile originator in the manufacture of pesticides,dyes, plastics, drugs,explosives, etc due to their $\pi$-bonding and hydrogen systems. They are also useful in the production of cosmetics, aspirin, sunscreens andhair dyes. Phenols are different from normal alcohols, since they are acidic owing to the influence of $\mathrm{OH}$ group with the aromatic ring [1]. Because of their moderate size and resemblance to biological species, Phenol derivatives are interesting molecules for computational studies. The addition of substituents in any system results in the change in charge distribution of molecules and ultimately affects all the molecular properties.

In recent years, phenol derivatives have been the common subjects of both theoretical and experimental effort because of their importance in industry as well as environment. Initially, the vibrational assignments of infrared spectrum of phenol have been studied by Evans [2]. Later, many studies of phenol derivatives have been extended by several researchers [3-5]. Recently, the experimental and DFT studies on many synthesized phenol derivatives have been investigated [6-7]. More recently, Soltani et al. [8] have

Revised Manuscript Received on December 29, 2019.

* Correspondence Author

Palani Murugan, Department of Physics, Dr. B.R. Ambedkar Institute of Technology, Port Blair-744103, Andaman \& Nicobar Islands, India Email : palanimuruganviji@gmail.com

S. Jeyavijayan*, Department of Physics , Kalasalingam Academy of Research and Education, Krishnankoil-626 126, Tamil Nadu, India Email : sjeyavijayan@gmail.com

M.S.Revathy, Department of Physics, Kalasalingam Academy of Research and Education, Krishnankoil-626 126,Tamil Nadu, India Email : revz.vijay@gmail.com

K. Gurushankar, Department of Physics, Kalasalingam Academy of Research and Education, Krishnankoil-626 126, Tamil Nadu, India Email : kgurumsc@yahoo.com studied the structural and other molecular properties of 4-bromo-2-(2,5-dichloro-phenylimino)-phenol. During the course of investigation on the phenol compounds, our consideration has been turned towards 3-chloro-5-methoxyphenol (CMOP). Since the superposition of several vibrations, the vibrational assignment of phenolsubstituents becomes difficult. On the other hand, the spectral comparison with the closely relative molecules provides specific clues regarding the molecular vibrations. In the present investigation, the vibrational spectra of the CMOP have been studied along with theoretical calculations and its various normal modes are identified with greater wave numbers precisely.

\section{EXPERIMENTAL}

The Fourier transform infrared spectra of CMOP was recorded in the region 4000-400 $\mathrm{cm}^{-1}$, using Perkin Elmer FTIR spectrometer and the FT-Raman spectrum of CMOP was recorded on a computer interfaced BRUKER RFS-66V model interferometer in the Stokes region $4000-50 \mathrm{~cm}^{-1}$. In this study, the DFT-B3LYP functional calculations have been worked out to get the structural and vibrational modes of CMOP. The molecular geometry optimizations, frequencies and other molecular parameters such as electronic, optical, etc were calculated for CMOP with the GAUSSIAN 09W software [9] at DFT level [10,11]. To confirm the vibrational assignment of CMOP, the total energy distribution (TED) were made with the MOLVIB program [12].

\section{RESULTS AND DISCUSSION}

The molecular structure of CMOP is shown in Fig. 1. The minimum energy for CMOP calculated by the DFT with $6-31+\mathrm{G}(\mathrm{d}, \mathrm{p})$ and 6-311++G(d,p) basis sets are -881.6170699 and -881.7378177 Hartrees, respectively. The optimization geometrical parameters of CMOP are listed in the Table I. From the Table I, the bond length order is C2-C3 < C1-C6 < C3-C4 < C5-C6 < C4-C5 < C1-C2, which indicates the hexagonal benzene ring structure with little indistinct. This is because of conjugation between the functional groups and the benzene ring. The inclusion of the hydroxy group, chlorine atom and methoxy group substitutions in benzene ring lead to a little distortion. This is evident from the bond angles value of C2-C1-C6, C2-C3-C4 and C4-C5-C6 which is found to be $121.17 \circ, 122.77^{\circ}$ and $120.93^{\circ}$, respectively, (B3LYP/6-31+(d,p) method) and are different from typical $120^{\circ}$. 


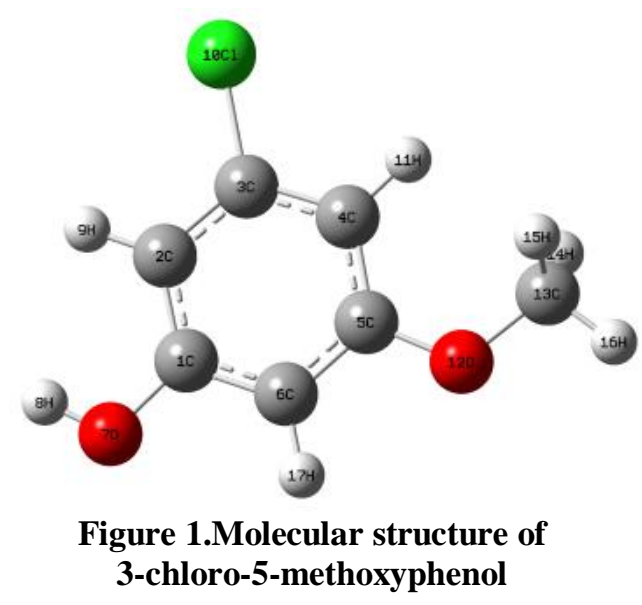

The CMOP contains of 17 atoms that will have 45 vibrational modes in accordance with $\mathrm{C}_{\mathrm{s}}$ point symmetry. The vibrational assignment of CMOP with the calculated frequencies and their intensities are reported in Table II. The experimental and theoretical spectra of CMOP are given in Figs. 2 and 3, respectively.

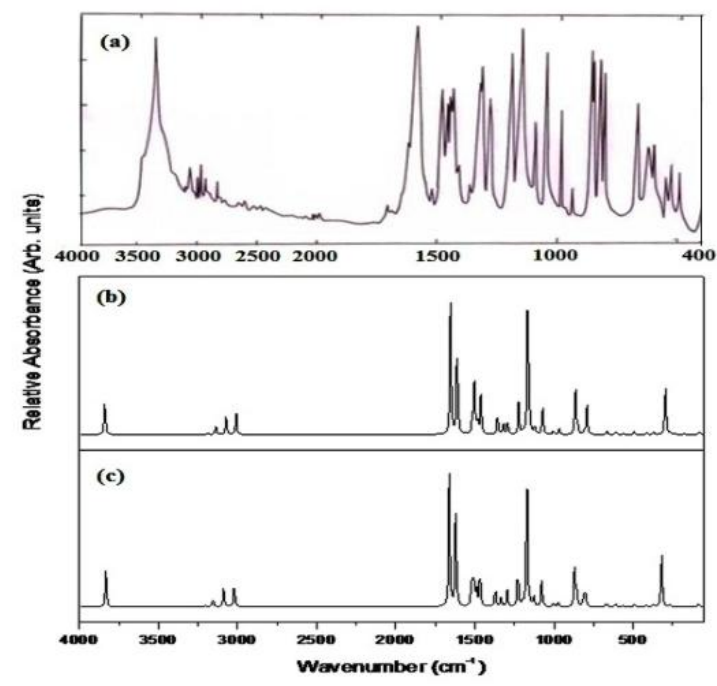

Figure 2. IR spectra of 3-chloro-5-methoxyphenol (a) B3LYP/6-31+G(d,p).

In the present investigation, the experimental are compared with the calculated frequencies at DFT-B3LYP level using the lower and higher basis sets, which reveals the overestimation of the computed frequencies. This may be due to ignorance of anharmonicity in actual system. From the Table II, the vibrational analysis of CMOP with the unscaled B3LYP force field is generally larger than the experimental frequencies and these discrepancies can be corrected by scaling the calculated frequencies with suitable scale factor [13].Therefore, a scale factor of 0.9613 is used for B3LYP method and the resultant scaled frequencies are listed in Table II.The frequencies of the stretching and bending vibration can be changed by $\mathrm{O}-\mathrm{H}$ bonding. The $\mathrm{O}-\mathrm{H}$ stretching modes appeared in the lesser frequencies range (3200-3550 $\mathrm{cm}^{-1}$ ) with maximum intensity and peak broadening [14].In phenol,the O-H in-plane and out-of-plane bending vibrations lies between the frequencies 1150-1250 $\mathrm{cm}^{-1}$ and 290-320 $\mathrm{cm}^{-1}$, respectively.In CMOP, the IR and Raman peaks found at 3485 and $3482 \mathrm{~cm}^{-1}$ are assigned to $\mathrm{O}-\mathrm{H}$ stretching vibration, respectively, which are further confirmed by the energy distribution of $99 \%$. The in-plane observed; (b) B3LYP/6-311++G(d,p); (c)

bending vibrations of hydroxyl group for CMOP have been identified at 1115 in both IR, Raman spectra. The out-of-plane bending vibrations of $\mathrm{O}-\mathrm{H}$ group are assigned at $160 \mathrm{~cm}^{-1}$ in Raman spectrum.

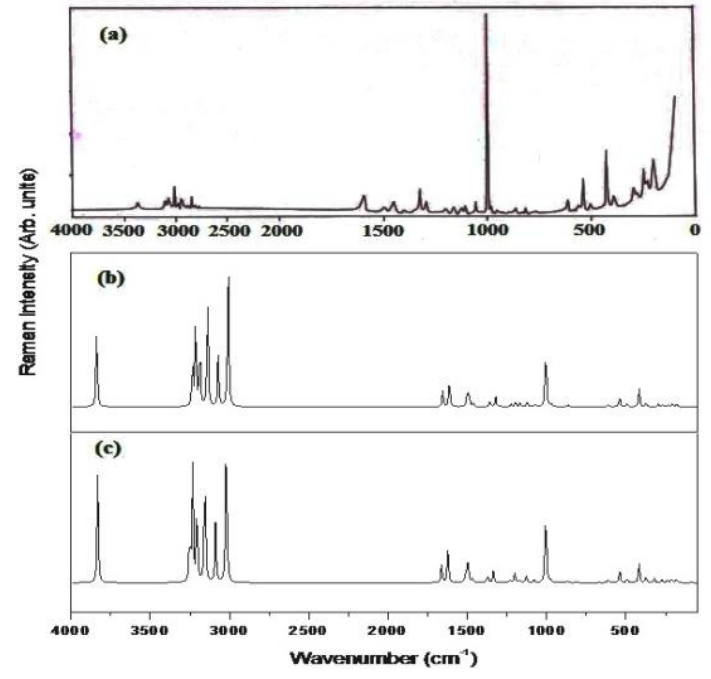

Figure 3.Raman spectra of 3-chloro-5-methoxyphenol (a) observed; (b) B3LYP/6-311++G(d,p); (c) B3LYP/6-31+G(d,p).

The aromatic $\mathrm{C}-\mathrm{H}$ stretching vibrations usually exhibit various weak bands around $3100-3000 \mathrm{~cm}^{-1}$ [15]. Generally, the $\mathrm{C}-\mathrm{H}$ in-plane bending and $\mathrm{C}-\mathrm{C}$ stretching vibrations interact with each other leading to strong bands around $1300-1000 \mathrm{~cm}^{-1}$. The $\mathrm{C}-\mathrm{H}$ out-of-plane bending vibrations are powerfully coupled vibrations and their bands lie in the region $900-667 \mathrm{~cm}^{-1}$. Hence, the IR peaks emerged at 3102 , $3085,3062 \mathrm{~cm}^{-1}$ and the Raman bands originated at 3104 , $3088,3060 \mathrm{~cm}^{-1}$ in CMOP were assigned to $\mathrm{C}-\mathrm{H}$ stretching and these normal modes are agreement with their energy distribution percentage.

In the title molecule CMOP, nine normal modes associated to each methyl group. The asymmetric and symmetric C-H stretching modes of methyl group [16] are estimated around $2980 \mathrm{~cm}^{-1}$ and $2870 \mathrm{~cm}^{-1}$, respectively. The experimental FTIR and FT-Raman spectra of CMOP have $\mathrm{CH}_{3}$ out-of-plane stretching bands at 2945 and 2940 $\mathrm{cm}^{-1}$, respectively. The $\mathrm{CH}_{3}$ stretching in-plane vibrations are designated at $3010 \mathrm{~cm}^{-1}$ in both vibrational spectra and they are in good agreement with the calculations by B3LYP/6-311++G(d,p) method. The $\mathrm{CH}_{3}$ ss modes are recognized at 2892 and $2890 \mathrm{~cm}^{-1}$ in the FTIR and Raman spectra, respectively. The symmetrical bend modes $\mathrm{CH}_{3} \mathrm{sb}$, is found at $1352 \mathrm{~cm}^{-1}$ in IR and $1355 \mathrm{~cm}^{-1}$ in Raman spectrum. The $\mathrm{CH}_{3}$ in-plane bending modes of CMOP are observed at 1455 and $1460 \mathrm{~cm}^{-1}$ in the IR and Raman spectra, respectively, and all these modes are also agreed with the literature data [16] as well as TED.The bands at $1430 \mathrm{~cm}^{-1}$ in Raman, is ascribed to $\mathrm{CH}_{3}$ out-of-plane bending of CMOP. The bands obtained at $928 \mathrm{~cm}^{-1}$ and $1120 \mathrm{~cm}^{-1}$ in the experimental spectra are consigned to $\mathrm{CH}_{3}$ in-plane and out-of-plane rocking modes, respectively, and they prove consistent agreement with the computed values. The halogen atoms appearance in the benzene ring is very important for discussion because the mixing of vibrations is probable in this region [17]. Usually, the $\mathrm{C}-\mathrm{Cl}$ bands appear in the broad region $850-550 \mathrm{~cm}^{-1}$. 
For CMOP, the band found at $830 \mathrm{~cm}^{-1}$ in IR and $832 \mathrm{~cm}^{-1}$ in the Raman have been allotted to $\mathrm{C}-\mathrm{Cl}$ stretching mode of vibration and the corresponding TED contribution is $74 \%$. In this study, the bands identified at 472 and $175 \mathrm{~cm}^{-1}$ in the
Raman have been assigned to the $\mathrm{C}-\mathrm{Cl}$ in-plane and out-of-plane deformations, respectively, and they are in fine concurrence with the previous literature [17].

Table I. Optimized geometrical parameters of 3-chloro-5-methoxyphenol obtained by DFT-B3LYP method

\begin{tabular}{|c|c|c|c|c|c|c|c|c|}
\hline \multirow{2}{*}{$\begin{array}{l}\text { Bond } \\
\text { length }\end{array}$} & \multicolumn{2}{|c|}{ Value ( $\AA$ ) } & \multirow{2}{*}{ Bond angle } & \multicolumn{2}{|c|}{ Value $\left(^{\circ}\right)$} & \multirow{2}{*}{ Dihedral Angle } & \multicolumn{2}{|c|}{ Value $\left(^{\circ}\right)$} \\
\hline & $\begin{array}{c}\text { B3LYP/ } \\
6-31+G(d, p)\end{array}$ & $\begin{array}{c}\text { B3LYP/ } \\
6-311++G(d, p)\end{array}$ & & $\begin{array}{c}\text { B3LYP/ } \\
6-31+G(d, p)\end{array}$ & $\begin{array}{c}\text { B3LYP/ } \\
6-311++G(d, p)\end{array}$ & & $\begin{array}{c}\text { B3LYP/ } \\
6-31+G(d, p)\end{array}$ & $\begin{array}{c}\text { B3LYP/ } \\
6-311++G(d, p)\end{array}$ \\
\hline $\mathrm{C} 1-\mathrm{C} 2$ & 1.404 & 1.401 & C2-C1-C6 & 121.17 & 121.07 & C6-C1-C2-C3 & 0.0 & 0.0 \\
\hline C1-C6 & 1.392 & 1.388 & $\mathrm{C} 2-\mathrm{C} 1-\mathrm{O} 7$ & 121.79 & 121.80 & C6-C1-C2-H9 & 180.0 & 180.0 \\
\hline $\mathrm{C} 1-\mathrm{O} 7$ & 1.368 & 1.367 & C6-C1-O7 & 117.03 & 117.14 & $\mathrm{O} 7-\mathrm{C} 1-\mathrm{C} 2-\mathrm{C} 3$ & 180.0 & 180.0 \\
\hline $\mathrm{C} 2-\mathrm{C} 3$ & 1.391 & 1.387 & $\mathrm{C} 1-\mathrm{C} 2-\mathrm{C} 3$ & 117.92 & 117.94 & $\mathrm{O} 7-\mathrm{C} 1-\mathrm{C} 2-\mathrm{H} 9$ & 0.0 & 0.0 \\
\hline $\mathrm{C} 2-\mathrm{H} 9$ & 1.085 & 1.083 & $\mathrm{C} 1-\mathrm{C} 2-\mathrm{H} 9$ & 121.41 & 121.37 & C2-C1-C6-C5 & 0.0 & 0.0 \\
\hline C3-C4 & 1.396 & 1.392 & C3-C2-H9 & 120.68 & 120.69 & C2-C1-C6-H17 & 180.0 & 180.0 \\
\hline $\mathrm{C} 3-\mathrm{Cl10}$ & 1.760 & 1.761 & C2-C3-C4 & 122.77 & 122.80 & O7-C1-C6-C5 & 180.0 & 180.0 \\
\hline C4-C5 & 1.403 & 1.400 & $\mathrm{C} 2-\mathrm{C} 3-\mathrm{Cl10}$ & 118.68 & 118.68 & O7-C1-C6-H17 & 0.0 & 0.0 \\
\hline C4-H11 & 1.081 & 1.079 & C4-C3-Cl10 & 118.55 & 118.52 & C2-C1-O7-H8 & 0.0 & 0.0 \\
\hline C5-C6 & 1.400 & 1.397 & C3-C4-C5 & 117.86 & 117.90 & C6-C1-O7-H8 & 180.0 & 180.0 \\
\hline C5-O12 & 1.363 & 1.361 & C3-C4-H1 1 & 119.83 & 119.81 & C1-C2-C3-C4 & 0.0 & 0.0 \\
\hline C6-H17 & 1.083 & 1.082 & C5-C4-H11 & 122.31 & 122.29 & C1-C2-C3-C110 & 180.0 & 180.0 \\
\hline O7-H8 & 0.966 & 0.963 & C4-C5-C6 & 120.93 & 120.80 & H9-C2-C3-C4 & 180.0 & 180.0 \\
\hline $\mathrm{O} 12-\mathrm{C} 13$ & 1.424 & 1.423 & $\mathrm{C} 4-\mathrm{C} 5-\mathrm{O} 12$ & 123.66 & 123.73 & H9-C2-C3-Cl10 & 0.0 & 0.0 \\
\hline $\mathrm{C} 13-\mathrm{H} 14$ & 1.097 & 1.095 & C6-C5-O12 & 115.41 & 115.48 & C2-C3-C4-C5 & 0.0 & 0.0 \\
\hline C13-H15 & 1.097 & 1.095 & C1-C6-C5 & 119.36 & 119.50 & C2-C3-C4-H11 & 180.0 & 180.0 \\
\hline \multirow[t]{15}{*}{$\mathrm{C} 13-\mathrm{H} 16$} & 1.091 & 1.088 & C1-C6-H17 & 120.55 & 120.47 & Cl10-C3-C4-C5 & 180.0 & 180.0 \\
\hline & & & C5-C6-H17 & 120.10 & 120.04 & Cl10-C3-C4-H11 & 0.0 & 0.0 \\
\hline & & & C1-O7-H8 & 110.18 & 109.95 & C3-C4-C5-C6 & 0.0 & 0.0 \\
\hline & & & $\mathrm{C} 5-\mathrm{O} 12-\mathrm{C} 13$ & 118.86 & 118.88 & C3-C4-C5-O12 & 180.0 & 180.0 \\
\hline & & & O12-C13-H14 & 111.32 & 111.36 & H11-C4-C5-C6 & 180.0 & 180.0 \\
\hline & & & O12-C13-H15 & 111.32 & 111.36 & H11-C4-C5-O12 & 0.0 & 0.0 \\
\hline & & & O12-C13-H16 & 105.65 & 105.71 & C4-C5-C6-C1 & 0.0 & 0.0 \\
\hline & & & H14-C13-H15 & 109.63 & 109.62 & C4-C5-C6-H17 & 180.0 & 180.0 \\
\hline & & & H14-C13-H16 & 109.41 & 109.35 & O12-C5-C6-C1 & 180.0 & 180.0 \\
\hline & & & H15-C13-H16 & 109.41 & 109.35 & O12-C5-C6-H17 & 0.0 & 0.0 \\
\hline & & & & & & C4-C5-O12-C13 & 0.0 & 0.0 \\
\hline & & & & & & C6-C5-O12-C13 & 180.0 & 180.0 \\
\hline & & & & & & C5-O12-C13-H14 & -61.32 & -61.34 \\
\hline & & & & & & C5-O12-C13-H15 & 61.32 & 61.34 \\
\hline & & & & & & C5-O12-C13-H16 & 180.0 & 180.0 \\
\hline
\end{tabular}

Table II.The observed FTIR, FT-Raman and calculated (unscaled and scaled) frequencies $\left(\mathrm{cm}^{-1}\right)$, IR intensity (km mol $\left.^{-1}\right)$, Raman activity $\left(\AA^{4} \mathrm{amu}^{-1}\right)$ and probable assignments (characterized by TED) of 3-chloro-5-methoxyphenol using B3LYP method

\begin{tabular}{|c|c|c|c|c|c|c|c|c|c|c|c|}
\hline \multirow{3}{*}{$\begin{array}{c}\text { Species } \\
\mathrm{C}_{\mathrm{s}}\end{array}$} & \multirow{2}{*}{\multicolumn{2}{|c|}{$\begin{array}{l}\text { Observed wavenumber } \\
\qquad\left(\mathrm{cm}^{-1}\right)\end{array}$}} & \multicolumn{8}{|c|}{ Calculated frequencies $\left(\mathrm{cm}^{-1}\right)$} & \multirow{3}{*}{$\begin{array}{c}\text { TED\% among } \\
\text { types of } \\
\text { coordinates }\end{array}$} \\
\hline & & & \multicolumn{4}{|c|}{ B3LYP/6-31+G(d,p) } & \multicolumn{4}{|c|}{ B3LYP/6-311++G(d,p) } & \\
\hline & FTIR & FT Raman & Unscaled & Scaled & $\begin{array}{c}\text { IR } \\
\text { intensity }\end{array}$ & $\begin{array}{l}\text { Raman } \\
\text { activity }\end{array}$ & Unscaled & Scaled & $\begin{array}{c}\text { IR } \\
\text { intensity }\end{array}$ & $\begin{array}{l}\text { Raman } \\
\text { activity }\end{array}$ & \\
\hline $\mathrm{A}^{\prime}$ & 3485 (vs) & $3482(\mathrm{vw})$ & 3831 & 3683 & 68.29 & 116.20 & 3838 & 3689 & 73.58 & 111.46 & vOH(99) \\
\hline $\mathrm{A}^{\prime}$ & $3102(w)$ & 3104(vw) & 3252 & 3126 & 0.53 & 51.04 & 3234 & 3109 & 0.60 & 48.50 & vCH(98) \\
\hline $\mathrm{A}^{\prime}$ & $3085(\mathrm{~ms})$ & 3088(vw) & 3233 & 3108 & 0.02 & 103.94 & 3214 & 3090 & 0.01 & 100.87 & vCH(96) \\
\hline $\mathrm{A}^{\prime}$ & $3062(\mathrm{~ms})$ & $3060(\mathrm{~ms})$ & 3205 & 3081 & 2.70 & 82.45 & 3188 & 3065 & 2.32 & 79.41 & $v \mathrm{CH}(94)$ \\
\hline $\mathrm{A}^{\prime}$ & $3010(\mathrm{~ms})$ & $3010(\mathrm{vw})$ & 3156 & 3034 & 18.96 & 129.67 & 3138 & 3017 & 18.99 & 125.20 & $\mathrm{CH}_{3 \mathrm{ips}}(92)$ \\
\hline $\mathrm{A}^{\prime}$ & 2892(ms) & $2890(w)$ & 3021 & 2904 & 51.23 & 148.31 & 3010 & 2894 & 47.73 & 159.73 & $\mathrm{CH}_{3 \mathrm{ss}}(90)$ \\
\hline $\mathrm{A}^{\prime}$ & $1585(\mathrm{vs})$ & $1580(w)$ & 1663 & 1599 & 262.48 & 11.58 & 1655 & 1591 & 255.32 & 11.65 & $v \mathrm{CC}(88)$ \\
\hline $\mathrm{A}^{\prime}$ & $1547(\mathrm{~ms})$ & & 1622 & 1559 & 215.52 & 24.43 & 1613 & 1551 & 214.65 & 23.20 & $v \mathrm{CC}(86)$ \\
\hline $\mathrm{A}^{\prime}$ & $1455(\mathrm{~s})$ & $1460(\mathrm{vw})$ & 1522 & 1463 & 52.86 & 1.20 & 1516 & 1457 & 47.10 & 1.09 & $\mathrm{CH}_{3 \mathrm{ipb}}(84)$ \\
\hline $\mathrm{A}^{\prime}$ & $1438(\mathrm{~s})$ & $1435(\mathrm{w})$ & 1508 & 1450 & 82.14 & 6.53 & 1503 & 1445 & 94.82 & 5.83 & $v \mathrm{CC}(85)$ \\
\hline $\mathrm{A}^{\prime}$ & $1424(\mathrm{~ms})$ & & 1489 & 1431 & 32.14 & 2.58 & 1483 & 1426 & 31.95 & 2.29 & $v \mathrm{CC}(84)$ \\
\hline $\mathrm{A}^{\prime}$ & 1402(w) & $1400(\mathrm{~ms})$ & 1468 & 1411 & 88.25 & 3.61 & 1462 & 1405 & 90.76 & 3.10 & $v \mathrm{CC}(82)$ \\
\hline $\mathrm{A}^{\prime}$ & $1352(\mathrm{w})$ & $1355(\mathrm{w})$ & 1371 & 1318 & 46.94 & 4.91 & 1357 & 1304 & 50.06 & 4.86 & $\mathrm{CH}_{3 \mathrm{sb}}(81)$ \\
\hline $\mathrm{A}^{\prime}$ & 1264(w) & & 1334 & 1282 & 20.89 & 8.36 & 1322 & 1271 & 22.13 & 7.88 & $v \mathrm{CC}(80)$ \\
\hline $\mathrm{A}^{\prime}$ & 1238(s) & & 1296 & 1246 & 30.92 & 0.26 & 1293 & 1243 & 30.74 & 0.30 & vCO(79) \\
\hline $\mathrm{A}^{\prime}$ & $1175(\mathrm{~s})$ & $1172(\mathrm{vw})$ & 1228 & 1180 & 87.73 & 2.07 & 1223 & 1176 & 62.98 & 1.77 & vCO $(80)$ \\
\hline $\mathrm{A}^{\prime}$ & $1148(s)$ & $1150(\mathrm{vw})$ & 1199 & 1153 & 6.76 & 5.16 & 1196 & 1150 & 6.25 & 4.88 & $v \mathrm{CO}(81)$ \\
\hline $\mathrm{A}^{\prime}$ & $1115(\mathrm{~s})$ & 1115(vw) & 1171 & 1126 & 317.26 & 0.35 & 1165 & 1120 & 342.78 & 0.32 & bOH(78) \\
\hline
\end{tabular}




\begin{tabular}{|c|c|c|c|c|c|c|c|c|c|c|c|}
\hline $\mathrm{A}^{\prime}$ & $1080(\mathrm{~ms})$ & 1076(w) & 1130 & 1086 & 21.37 & 4.39 & 1124 & 1081 & 20.75 & 4.66 & bCH(79) \\
\hline $\mathrm{A}^{\prime}$ & 1031(s) & $1030(\mathrm{vs})$ & 1079 & 1037 & 52.40 & 1.63 & 1074 & 1032 & 56.40 & 1.68 & $\mathrm{bCH}(76)$ \\
\hline $\mathrm{A}^{\prime}$ & $970(\mathrm{~s})$ & $968(\mathrm{vw})$ & 1005 & 966 & 8.73 & 48.56 & 1005 & 966 & 9.98 & 46.90 & $\mathrm{bCH}(78)$ \\
\hline $\mathrm{A}^{\prime}$ & 928(ms) & $928(\mathrm{vw})$ & 974 & 936 & 9.90 & 1.46 & 968 & 931 & 10.26 & 1.40 & $\mathrm{CH}_{3 \mathrm{ipr}}(75)$ \\
\hline$A^{\prime}$ & $830(\mathrm{~s})$ & $832(\mathrm{vw})$ & 869 & 835 & 99.00 & 1.17 & 866 & 832 & 101.33 & 1.18 & $v \mathrm{CCl}(74)$ \\
\hline $\mathrm{A}^{\prime}$ & $582(\mathrm{~ms})$ & $585(\mathrm{vw})$ & 613 & 589 & 3.11 & 1.43 & 612 & 588 & 3.00 & 0.99 & $\mathrm{bCO}(74)$ \\
\hline $\mathrm{A}^{\prime}$ & $576(\mathrm{~ms})$ & $575(\mathrm{vw})$ & 606 & 583 & 3.52 & 0.62 & 607 & 584 & 3.46 & 0.59 & $\mathrm{bCO}(76)$ \\
\hline $\mathrm{A}^{\prime}$ & $515(\mathrm{~ms})$ & $510(w)$ & 539 & 518 & 0.28 & 7.34 & 539 & 518 & 0.39 & 7.20 & $\mathrm{bCO}(73)$ \\
\hline $\mathrm{A}^{\prime}$ & - & 472(s) & 493 & 474 & 6.91 & 2.18 & 494 & 475 & 7.29 & 2.17 & bCCl(72) \\
\hline $\mathrm{A}^{\prime}$ & - & 398(w) & 418 & 402 & 3.82 & 9.82 & 417 & 401 & 3.68 & 9.71 & R symd (72) \\
\hline $\mathrm{A}^{\prime}$ & - & $354(w)$ & 373 & 359 & 5.16 & 3.20 & 372 & 358 & 5.23 & 3.11 & $\mathrm{R}$ trigd (70) \\
\hline $\mathrm{A}^{\prime}$ & - & $247(\mathrm{vw})$ & 269 & 259 & 4.29 & 1.38 & 262 & 252 & 1.43 & 0.20 & $\mathrm{R}$ asymd (74) \\
\hline $\mathrm{A}^{\prime \prime}$ & $2945(\mathrm{~ms})$ & $2940(w)$ & 3087 & 2968 & 34.96 & 52.81 & 3071 & 2952 & 33.67 & 51.89 & $\mathrm{CH}_{3 \mathrm{ops}}(86)$ \\
\hline $\mathrm{A}^{\prime \prime}$ & - & $1430(\mathrm{vw})$ & 1498 & 1440 & 8.66 & 13.70 & 1493 & 1435 & 9.75 & 13.12 & $\mathrm{CH}_{3 \mathrm{opb}}(82)$ \\
\hline $\mathrm{A}^{\prime \prime}$ & - & $1120(\mathrm{vw})$ & 1171 & 1126 & 0.94 & 1.88 & 1166 & 1121 & 0.59 & 2.80 & $\mathrm{CH}_{3 \mathrm{opr}}(80)$ \\
\hline $\mathrm{A}^{\prime \prime}$ & $815(s)$ & - & 855 & 822 & 22.69 & 0.13 & 850 & 817 & 17.61 & 0.16 & $\omega \mathrm{CH}(68)$ \\
\hline $\mathrm{A}^{\prime \prime}$ & $776(s)$ & $775((w)$ & 818 & 786 & 11.42 & 0.37 & 810 & 779 & 7.34 & 0.07 & $\omega \mathrm{CH}(65)$ \\
\hline $\mathrm{A}^{\prime \prime}$ & $758(\mathrm{~s})$ & $760(\mathrm{vw})$ & 804 & 773 & 46.26 & 0.29 & 793 & 762 & 55.51 & 0.07 & $\omega \mathrm{CH}(63)$ \\
\hline $\mathrm{A}^{\prime \prime}$ & $635(\mathrm{~ms})$ & $634(w)$ & 668 & 642 & 9.21 & 0.13 & 666 & 640 & 7.77 & 0.03 & tR symd (62) \\
\hline $\mathrm{A}^{\prime \prime}$ & $538(\mathrm{~ms})$ & $540(\mathrm{~ms})$ & 564 & 542 & 2.39 & 0.08 & 563 & 541 & 1.91 & 0.17 & tR trigd (64) \\
\hline $\mathrm{A}^{\prime \prime}$ & - & $290(\mathrm{vw})$ & 322 & 310 & 109.28 & 2.35 & 298 & 286 & 104.95 & 1.87 & tR asymd (66) \\
\hline $\mathrm{A}^{\prime \prime}$ & - & $255(w)$ & 272 & 261 & 0.24 & 0.21 & 268 & 258 & 4.19 & 1.42 & $\omega \mathrm{CO}(61)$ \\
\hline $\mathrm{A}^{\prime \prime}$ & - & $220(v w)$ & 237 & 228 & 0.63 & 1.45 & 235 & 226 & 0.82 & 1.16 & $\omega \mathrm{CO}(62)$ \\
\hline $\mathrm{A}^{\prime \prime}$ & - & $205(\mathrm{vw})$ & 212 & 204 & 0.01 & 2.11 & 207 & 199 & 0.00 & 1.84 & $\omega \mathrm{CO}(64)$ \\
\hline $\mathrm{A}^{\prime}$ & - & $175(w)$ & 181 & 174 & 1.83 & 2.06 & 180 & 173 & 1.78 & 2.16 & $\omega \mathrm{CCl}(62)$ \\
\hline $\mathrm{A}^{\prime \prime}$ & - & $160(\mathrm{vw})$ & 166 & 160 & 0.23 & 0.11 & 163 & 157 & 0.24 & 0.08 & $\omega \mathrm{OH}(61)$ \\
\hline $\mathrm{A}^{\prime \prime}$ & - & - & 85 & 85 & 6.92 & 0.29 & 82 & 82 & 6.79 & 0.28 & $\mathrm{tOCH}_{3}(58)$ \\
\hline
\end{tabular}

The C-C stretching vibrations bands appear in between 1400 and $1650 \mathrm{~cm}^{-1}$ in benzene derivatives [18]. Hence, the C-C stretching modes of CMOP are established at 1585, $1547,1438,1424,1402,1264 \mathrm{~cm}^{-1}$ in FTIR and 1580, 1435, $1400 \mathrm{~cm}^{-1}$ in the FT-Raman spectrum. The C-C in-plane and out-of-plane bending modes of CMOP are well identified within their characteristic region in the recorded spectra and the TED \% show reliable agreement with the vibrational assignment. For carbonyl contained compounds, the strongest peaks in the region $1260-1000 \mathrm{~cm}^{-1}$ are due to the C-O stretching modes. Therefore, the strongest IR bands at $1238,1175,1148 \mathrm{~cm}^{-1}$ and Raman bands at $1172,1150 \mathrm{~cm}^{-1}$ in CMOP were assigned to the $\mathrm{C}-\mathrm{O}$ stretching vibration modes andthese are supported with the previous assignments [19].

The electronic, optical properties and chemical reactions of the molecules are decided by the highest occupied and lowest unoccupied molecular orbitals (HOMOs and LUMOs) [20]. The atomic orbital compositions for CMOP are shown in Fig. 4. The calculations indicate that the title molecule have 41 occupied MOs. The HOMO is located over $\mathrm{OH}$ group, chlorine atom and methoxy group; The LUMO of ring is distributed over the entire $\mathrm{C}-\mathrm{C}$ bond. The HOMO to LUMO transition explains the transfer of electron density to $\mathrm{C}-\mathrm{C}$ bond of the benzene ring from $\mathrm{OH}$ group, chlorine atom and methoxy group. The energy gap of CMOP reveals the chemical motion and reactivity of the molecule.

The calculation of atomic charges describes a significant task in the application of DFT calculations to molecular structure [21]. Mulliken population analysis has been carried out for the comparison of different choice of the basis sets to illustrate the electron sharing in CMOP. The Fig.5 shows Mulliken's plot of CMOP. The carbon atoms C1, C3 and C5 have the high negative charge since they are attached with

$\mathrm{OH}, \mathrm{Cl}$ and an $\mathrm{O}-\mathrm{CH}_{3}$ group, respectively, which leads to rearrangement of electron concentration and every hydrogen have a positive charge because they are electron acceptors.

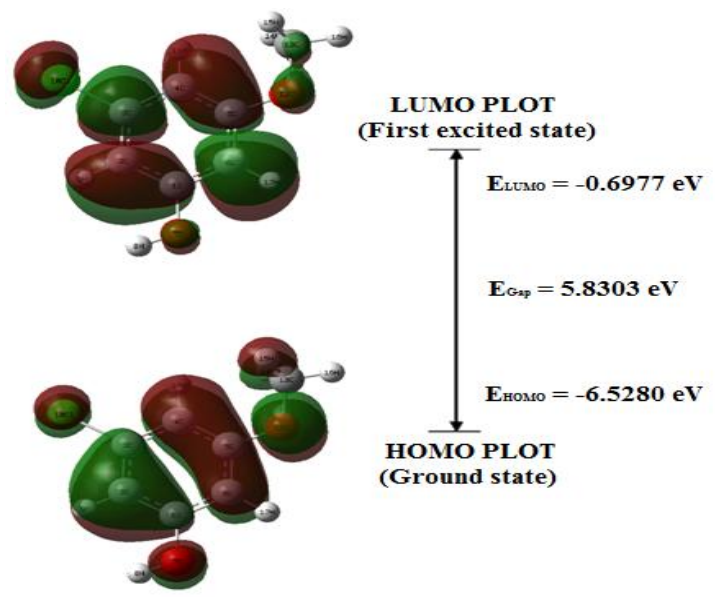

\section{Figure 4. The atomic orbital HOMO and LUMO compositions for 3-chloro-5-methoxyphenol}

The electrostatic potential has been utilized to predict sites and relative reactivities in the direction of electrophilic attack [22]. In the present investigation, the molecular electrostatic potential (MEP) map for CMOP is revealed in Fig. 6. The blue (positive) regions of MEP are related to nucleophilic reactivity and the red and yellow (negative) regions to electrophilic reactivity as shown. In the present study, the MEP map shows that the negative potential sites around chlorine and oxygen atoms (Red) and the positive potential sites are on the hydrogen atoms of the benzene ring (Blue). 
From these calculated results, the $\mathrm{H}$ atoms of the system show the strongest attraction and chlorine and oxygen atoms show the strongest repulsion. These sites provide details regarding the region of intermolecular interactions of CMOP.

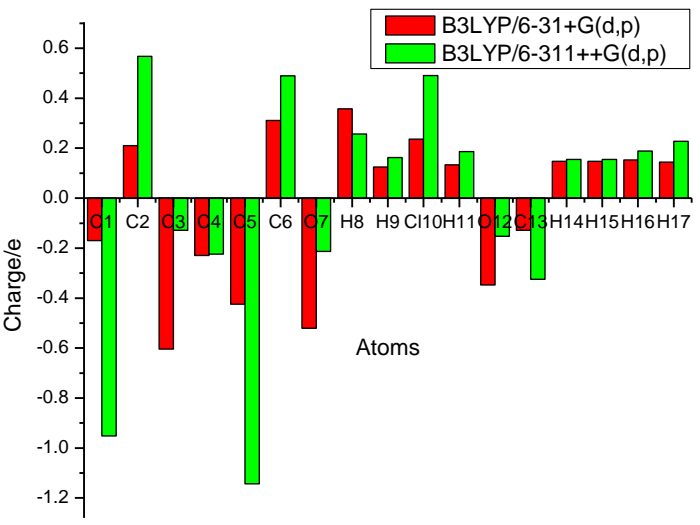

Figure 5.Mulliken's plot for 3-chloro-5-methoxyphenol

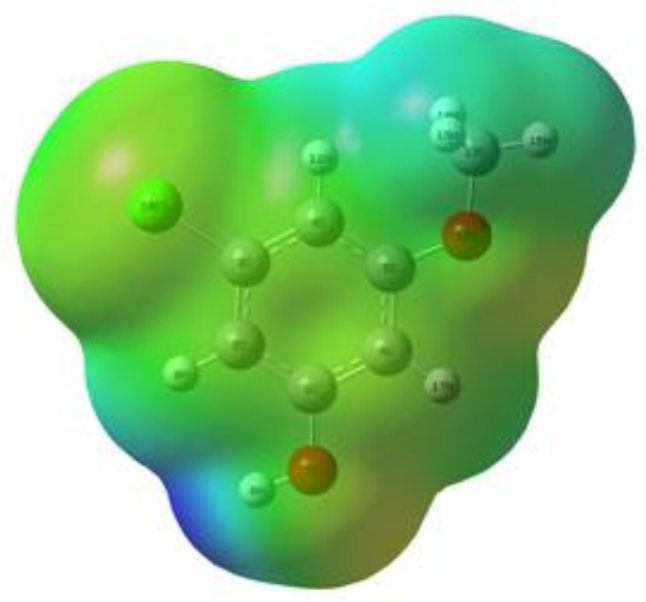

Figure 6. Molecular electrostatic potential (MEP) map for 3-chloro-5-methoxyphenol

Natural Bond Orbital (NBO) analysis is the important tools for localization of the molecular wave functions in optimized electron pairs, equivalent to lone pairs; core pairs on bonding units. In the present study, the change in electron density (ED) of $\left(\sigma^{*}, \pi^{*}\right)$ antibonding orbitals and $\mathrm{E}(2)$ energies have been calculated using DFT method with the Gaussian 09W package to give clear evidence of stabilization interactions [23]. The NBO basis of CMOP indicates the orbital intramolecular interactions of $\pi(\mathrm{C} 1-\mathrm{C} 6)$ with $\pi^{*}(\mathrm{C} 4-\mathrm{C} 5)$, resulting in high electron density (approx. $0.206 \mathrm{e}$ ) of anti-bonding $\pi$ orbitals (C-C) which causing stabilization of $12.88 \mathrm{kcal} / \mathrm{mol}$ to the system. Similarly, the charge transfer from $\pi(\mathrm{C} 2-\mathrm{C} 3)$ to $\pi^{*}(\mathrm{C} 1-\mathrm{C} 6)$ amounts to the stabilization of $10.77 \mathrm{kcal} / \mathrm{mol}$ and the charge transfer from $\pi(\mathrm{C} 4-\mathrm{C} 5)$ to $\pi^{*}(\mathrm{C} 2-\mathrm{C} 3)$ leads to the stabilization of 13.15 $\mathrm{kcal} / \mathrm{mol}$. Further, the charge transfer from the lone pairs of $\mathrm{O} 7$ to anti-bonding $\mathrm{C} 1-\mathrm{C} 6, \pi$ orbital amount to the stabilization of $13.80 \mathrm{kcal} / \mathrm{mol}$, while the lone pairs of chlorine $\mathrm{n} 3(\mathrm{Cl10}) \rightarrow \pi^{*}(\mathrm{C} 2-\mathrm{C} 3)$ and oxygen $\mathrm{n} 2(\mathrm{O} 12) \rightarrow$ $\pi^{*}(\mathrm{C} 4-\mathrm{C} 5)$, it is of the order of 6.46 and $15.61 \mathrm{kcal} / \mathrm{mol}$, respectively. Hence, there is a possibility for hyper conjugation between chlorine, oxygen atoms and the benzene ring.

\section{CONCLUSION}

The geometrical parameters, frequencies and vibrational intensities of 3-chloro-5-methoxyphenol have been carried out using the DFT-B3LYP method. The theoretical and experimental results were compared and provide the most consistent theoretical information on the molecular properties of CMOP. The calculated HOMO and LUMO energies show the occurrence of charge transfer which explains the chemical activity of the molecule. The Mulliken charge analysis explains the rearrangement of electron concentration in the molecule. The MEP surface predicts the relative reactivities towards electrophilic (hydrogen atoms) and nucleophilic (oxygen atoms) attacks. The NBO results imitate the electron transfer mostly because of the lone pair of chlorine $\mathrm{n} 3(\mathrm{Cl1}) \rightarrow \pi^{*}(\mathrm{C} 2-\mathrm{C} 3)$ and oxygen $\mathrm{n} 2(\mathrm{O} 12) \rightarrow$ $\pi^{*}(\mathrm{C} 4-\mathrm{C} 5)$.

\section{REFERENCES}

1. N.Sundaraganesan,B.Anand,C. Meganathan andB. Dominic Joshua, "FT-IR, FT-Raman spectra and ab initio HF, DFT vibrational analysis of 2,3-difluoro phenol,"Spectrochim. Acta A Mol. Biomol. Spectrosc., vol. 68,2007 , pp. 561-566.

2. J.C.Evans, The vibrational spectra of phenol and phenol-OD. Spectrochim. Acta, vol.16,1960, pp. 1382-1392.

3. J.Huang,K. Huang,S. Liu, Q.Luo and W.Tzeng ,"Vibrational spectra and theoretical calculations of p-chlorophenol in the electronically excited S1 and ionic ground D0 states,"J. Photochem. Photobiol. A Chem., vol. 193, 2008, pp. 245-253.

4. G.Wang,X. Gong,Y. Liu andH. Xiao, "A theoretical study on the vibrational spectra and thermodynamic properties for the nitro derivatives of phenols,"Spectrochim. Acta A Mol. Biomol. Spectrosc., vol. 74, 2009, pp. 569-574.

5. D.Mahadevan, S.Periandy, and S.Ramalingam, "Vibrational spectroscopy (FTIR and FTRaman) investigation using ab initio (HF) and DFT (B3LYP) calculations on the structure of 3-Bromo phenol,"Spectrochim. Acta A Mol. Biomol. Spectrosc., vol. 78, 2011 , pp. 575-58.

6. T.Tang, G.Tang, S.Kou, J.Zhao,L.F. Culnane andY. Zhang, "Experimental and DFT studies on the vibrational and electronic spectra of 2-(1H-Imidazo $[4,5-f][1,10]$ phenanthrolin-2-yl)phenol,"Spectrochim. Acta A Mol Biomol. Spectrosc., vol. 117, pp. 144-151,2014

7. M.Ghasemian, A.Kakanejadifard and T.Karami, "Synthesis, structural characterization, antimicrobial activities and theoretical investigations of some 4-(4-aminophenylsulfonyl) phenylimino) methyl)-4-(aryldiazenyl) phenol,"Spectrochim. Acta A Mol. Biomol. Spectrosc., vol.168, 2.16, pp.190-198.

A. Soltani, M.B.Javan,S.G. Raz, R.Mashkoor,A.D. Khalaji, M.Dusek, K.Fejfarova, L.Palatinus,J. Rohlicek andP. Machek, "Crystallography, vibrational, electronic and optical analysis of 4-Bromo-2-(2,5-dichloro-phenylimino)-phenol,"J. Mol. Struct., vol. 1173,2018 , pp. 521-530,

8. H.J. Frisch, G.W. Trucks, H.B. Schlegel, G.E. Scuseria, M.A. Robb, J.R. Cheeseman, H.Nakatsuji, M. Caricato, X. Li, H.P. Hratchian, K. Toyota, R. Fukuda, J.Hasegawa, M. Ishida, R. Nakajima, Y. Honda, O. Kilao, H. Nakai, T. Verven, J. A. Montgomery Jr., J.E. Peralta, F. Ogliaro, M. Bearpark, J. J. Heyd, E. Brothers, K. N. Kudin, V.N Staroveror, R. Kobayashi, J. Normand, K. Ragavachari, A. Rendell, J.C. Burant, S. J. Tomasi, M. Cossi, N. Rega, J. M. Millam, M. Klene, J. E. Knox, J. B. Cross, V. Bakken, C. Adamo, J. Jaramillo, R Gomperts, R.E. Strattmann, O. Yazyev, A.J. Austin, R. Cammi, J.W. Ochetrski, R.L. Martin, K. Morokuma, V.G. Zakrazawski, G.A.Votn, P. Salvador, J.J. Dannenberg, S. Dapprich, A.D. Daniels, O. Farkas and J.B. Foresman, Gaussian O.G., Revision A.O2, Gaussian Inc., Wallingford, CT. 2009.

9. A.D.Becke, "Densityfunctional thermochemistry. III. The role of exact exchange,"J. Chem. Phys., vol. 98,1993, pp. 5648-5652.

10. Lee, W.Yang and R.G.Parr, "Development of the Colle-Salvetti correlation-energy formula into a functional of the electron density,"Phys. Rev. B, vol. 37, 1988, pp. 785-789. 
11. T.Sundius, Scaling of ab initio force fields by MOLVIB, Vib. Spectrosc., vol. 29,2002, pp. 89-95.

12. D.C. Young, Computational Chemistry: A Practical Guide for Applying Techniques to Real World Problems (Electronic), 2001, John Wiley \& Sons Ltd., New York.

13. M.Arivazhagan andV. Krishnakumar,"Normal coordinate analysis of 1-chloroisoquinoline and 2-methyl-8-nitroquinoline,"Indian J. Pure Appl. Phys., vol. 43,2005, pp. 573-578.

14. Sajan,J. Binoy, I.Hubert Joe, V.S. Jayakumar andJ. Zaleski, "Vibrational spectral studies of methyl 3-(4-methoxyphenyl)prop-2-enoate, a new organic non-linear optic crystal,"J. Raman Spectrosc., vol. 36,2005, pp. 221-236.

15. B.Smith, Infrared Spectral Interpretation: A Systematic Approach, 1999, CRC Press, Washington, DC,

16. D.M.Chemes,D.J.A. de Armiño, E.H. Cutin, H. Oberhammer and N.L.Robles, "Synthesis, characterization and vibrational studies of p-chlorosulfinylaniline,"J. Mol. Struct., vol. 1127,2017, pp. 191-198.

17. P.Anbarasu,M.Arivazhagan andV. Balachandran, "Scaled quantum mechanical study of 2-acetylfluorene,"Indian J. Pure Appl. Phys., vol 50,2012, pp. 91-99.

18. T.Chithambarathanu,V.Umayourbhagan andV. Krishnakumar, "Vibational assignments of 2,6-di(p-methoxyphenyl)-3-methyl piperidone, 2,6-di(p-methyl phenyl)-3-methyl piperidone, 2,6-di(o-hydroxy phenyl)-3-methyl piperidone and 1-methyl-2,6 (p-methoxyphenyl) piperidone,"Indian J. Pure Appl. Phys., vol. 40,2002, pp. 72-74.

19. Fleming, Frontier Orbitals and Organic Chemical Reactions, 1976, Wiley, London.

20. S.Gunasekaran,S. Kumaresan,R. Arunbalaji, G.Anand and S.Srinivasan, "Density functional theory study of vibrational spectra, and assignment of fundamental modes of dacarbazine,"J. Chem. Sci., vol. 120(3),2008,pp. 315-324.

21. J.S. Murray andK. Sen, Molecular Electrostatic Potentials, Concepts and Applications, Elsevier, Amsterdam, 1996, pp. 7-624,

22. E.D.Glendening,J.K. Badenhoop, A.E.Reed, J.E.Carpenter, J.A.Bohmann,C.M. Morales and F.Weinhold, NBO 5.0, 2001, Theoretical Chemistry Institute, University of Wisconsin, Madison.

\section{AUTHORS PROFILE}

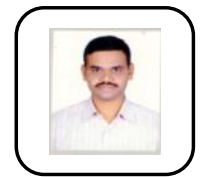

Palani Murugan has completed M.Sc from Bharathiar University, Coimbatore and M.Phil from Bharathidasan University, Tiruchirapalli. Presently working as Lecturer, Physics, in DR.B.R.Ambedkar Institute of Technology Port Blair since June 2012 Currently pursuing Ph.D from Kalasalingam Academy of Research and Education.

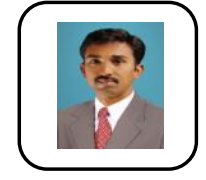

S. Jeyavijayan has completed M.Sc. and Ph.D. from Bharathidasan University, Trichirappalli in 2014.Currently working as Assistant Professor in Kalasalingam Academy of Research and Education from June 2015 onwards. Published more than 25 papers in National and International Journals. His fields of interest are Molecular Spectroscopy and Theoretical and Computational chemistry.

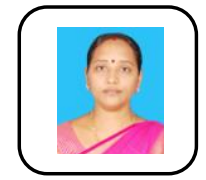

M. S. Revathy, has completed her Ph.D in Anna University in 2016. She has done M.Sc., M.Phil Physics in Mother Teresa Women's University, Kodaikanal. Currently working as Assistant Professor in Department of Physics, Kalasalingam Academy of Research and Education and her field of interests are thin films and green synthesis of nanomaterials. She has published 6 papers in national and international journals.

K. Gurushankar has completed M.Sc. and M.Phil., Ph.D. from Annamalai University Chidambaram in 2015. Joined as Assistant Professor at Kalasalingam University from June 2016 onwards. His fields of interest are "Applied spectroscopy in biological field". He has published 12 papers in leading International Journals. 